\title{
Substrate consumption and excess sludge reduction of activated sludge in the presence of uncouplers: a modeling approach
}

\author{
Wen-Ming Xie • Bing-Jie Ni • Guo-Ping Sheng • \\ Han-Qing Yu • Min Yang
}

Received: 7 July 2009 /Revised: 3 September 2009/Accepted: 9 September 2009/Published online: 7 November 2009

(C) Springer-Verlag 2009

\begin{abstract}
A mathematical model with a consideration of energy spilling is developed to describe the activated sludge in the presence of different levels of metabolic uncouplers. The consumption of substrate and oxygen via energy spilling process is modeled with a Monod term, which is dependent on substrate and inhibitor. The sensitivity of the developed model is analyzed. Three parameters, maximum specific growth rate $\left(\mu_{\max }\right)$, energy spilling coefficient $\left(q_{\max }\right)$, and sludge yield coefficient $\left(Y_{\mathrm{H}}\right)$ are estimated with experimental data of different studies. The values of $\mu_{\max }$, $q_{\max }$, and $Y_{\mathrm{H}}$ are found to be $6.72 \mathrm{day}^{-1}, 5.52 \mathrm{day}^{-1}$, and

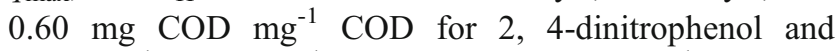
7.20 day $^{-1}, 1.58$ day $^{-1}$, and $0.62 \mathrm{mg} \mathrm{COD} \mathrm{mg}{ }^{-1}$ COD for 2, 4-dichlorophenol. Substrate degradation and sludge yield could be predicted with this model. The activated sludge process in the presence of uncouplers that is described more reasonably by the new model with a consideration of energy spilling. The effects of uncouplers on substrate consumption inhibition and excess sludge reduction in activated sludge are quantified with this model.
\end{abstract}

Keywords Activated sludge · Energy spilling · Modeling · Sludge yield · Substrate consumption $\cdot$ Uncoupler

W.-M. Xie • B.-J. Ni • G.-P. Sheng • H.-Q. Yu ( $\bowtie)$

Department of Chemistry,

University of Science and Technology of China,

Hefei 230026, China

e-mail: hqyu@ustc.edu.cn

M. Yang

State Key Laboratory of Environmental Aquatic Chemistry,

Research Center for Eco-Environmental Sciences,

Chinese Academy of Sciences,

Beijing 100085, China

\section{Introduction}

The activated sludge process is widely used for municipal and industrial wastewater treatment and also generates a large quantity of excess sludge daily. Treatment and disposal of the excess sludge account for $40-60 \%$ of the total capital and operation costs. Thus, the minimization of excess sludge production should be highly desirable. There are a few approaches for excess sludge reduction through either sludge pretreatment or microbial growth limitation (Low and Chase 1999). The latter seems to be more attractive than the former in terms of cost-effectiveness (Chen et al. 2002).

In order to limit the microbial growth, metabolic uncouplers have been used to reduce excess sludge production (Chen et al. 2002), which are able to disassociate the energy coupling between catabolism and anabolism, thereby, resulting in dissipation of certain portions of energy through futile cycles (Cook and Russell 1994). Under usual conditions, catabolism is coupled tightly with the anabolism in light of energy requirement. Thus, energy uncoupling does not occur. However, under some unusual conditions, such as high temperature, nutrient limitation, and the presence of metabolic uncouplers, energy uncoupling will occur (Forrest 1969; Tempest and Niejssel 1992; Tsai and Lee 1990). Therefore, maximization of the abnormal conditions will possibly lead to a significant energy uncoupling and reduce the sludge growth effectively (Chen et al. 2002).

Chen et al. (2006a, b) reported the response of activated sludge to the presence of dCP (2, 4-dichlorophenol) and dNP (2, 4-dinitrophenol) in batch cultures and established a Monod-type model with a consideration of inhibition to simulate the sludge reduction. An inhibition coefficient of microbial growth $K_{\mathrm{i}, \mathrm{u}}$ was proposed to reflect the inhibition 
degree of inhibitors on the substrate removal in their model. Unfortunately, this inhibition coefficient could not reflect the kinetic characteristics with uncouplers at different concentrations.

Liu et al. (1999) proposed a kinetic model incorporating energy spilling for substrate removal in a substratesufficient batch culture of activated sludge. Recently, Saini and Wood (2008) developed an empirical model to quantify the uncoupling effects of both excess substrate and uncoupler dose on the microbial cultures. The substrate was consumed with pure culture as three parts, including growth, maintenance, and energy spilling in that study. To mixed cultures, energy spilling should also be included in substrate consumption in the presence of uncouplers (Chen et al. 2002).

For a biological wastewater treatment system, its optimization requires a lot of experimental input. Therefore, a simulation model is desirable for such an optimization. The model simulation and prediction could provide a solid foundation for design and operation of the system. Thus, a mathematical model for describing the activated sludge in the presence of uncouplers is essential.

For the conventional activated sludge systems, activated sludge models (ASMs) established by the International Water Association provide a consistent framework for the description of biological processes in activated sludge processes, including carbon oxidation, nitrification, and denitrification (Gujer et al. 1999; Henze et al. 1987). However, for a system in the presence of uncoupler in activated sludge, ASMs are not able to appropriately describe the activated sludge. In this case, the energy spilling process should be taken into account in the models. In addition, effects of different uncoupler concentrations on the excess sludge reduction of activated sludge systems should be properly quantified. Therefore, a mathematical model should be developed to describe the excessive sludge reduction in the presence of uncouplers.

Therefore, the main objective of this study was to develop a kinetic model to describe the substrate consumption and excess sludge reduction in the activated sludge processes in the presence of uncouplers after taking into account energy spilling associated substrate consumption. In this model, the effects of uncouplers on substrate consumption inhibition and excess sludge reduction were quantified.

\section{Model development and calculation}

In the presence of an uncoupler, there is a discrepancy between the rate of energy production by catabolism and the rate of energy utilization by anabolism in activated sludge, i.e., energy uncoupling (Chen et al. 2006a, b). This results in nongrowth-associated energy consumption. The overall consumption of substrate $(\Delta S)_{\text {obs }}$ should be the sum of the substrate consumed for growth $\left(\Delta S_{\mathrm{g}}\right)$, the substrate consumed for maintenance $\left(\Delta S_{\mathrm{m}}\right)$, and the substrate consumed due to energy spilling $\left(\Delta S_{\mathrm{w}}\right)$ (Chen et al. 2002).

$(\Delta S)_{\mathrm{obs}}=\Delta S_{\mathrm{g}}+\Delta S_{\mathrm{m}}+\Delta S_{\mathrm{w}}$

The energy spilling model proposed in our work is structured with six model components or state variables, i.e., heterotrophic microorganisms $\left(X_{\mathrm{H}}\right)$, readily biodegradable substrate $\left(S_{\mathrm{S}}\right)$, slowly hydrolyzed particulate substrate $\left(X_{\mathrm{S}}\right)$, residual particulate inert biomass $\left(X_{\mathrm{I}}\right)$, and dissolved oxygen $\left(S_{\mathrm{O}}\right)$. This model basically involves five main microbial processes: heterotrophic growth with inhibition, maintenance, energy spilling, decay, and hydrolysis. Related process kinetics and stoichiometry, describing the interactions and transformations among model components, are expressed in such a way that is compatible with previous mathematical models, which have been proposed to formulate biochemical reactions of microbial populations fed with different type of substrates (Henze et al. 2000).

The structure of the proposed model is presented in a matrix format reflecting the basic stoichiometric relationships constituting the backbone of the model (Henze et al. 2000). The matrix format is outlined in Table 1, where model components are listed in the upper row; the rightmost column gives the process rate expressions; and the relevant stoichiometric coefficients are incorporated in appropriate matrix cells. In this way, the rate of change (generation or utilization) in a model component for a given biochemical process is obtained by multiplication of related process stoichiometry and kinetics (Gujer and Larsen 1995). All the parameters used in this model, their symbols, and their units are defined in Table 2.

The new energy spilling process is defined by a Monodtype expression as commonly adopted in other models. According to chemiosmotic theory, the oxidative phosphorylation is driven by proton gradient built up across cell membrane (Mitchell and Moyle 1965). In the presence of an uncoupler, the energy generated from the oxidation of organic substrate would be lost as heat rather than being captured in ATP (Liu 2003). As a result, the stoichiometry for energy spilling process is just related to substrate. Both $S_{\mathrm{S}}$ and $S_{\mathrm{O}}$ is consumed with a stoichiometry of -1 . Furthermore, the difference between the relative specific growth rate $\left(\mu / \mu_{\mathrm{O}}\right)$ and the relative specific substrate removal rate $\left(q / q_{\mathrm{O}}\right)$ increase with the increasing uncoupler concentration in batch tests (Chen et al. 2006a, b), suggesting that the energy spilling rate is positively related to the uncoupler concentration. Thus, the kinetic expression of energy spilling process is defined as follows:

$\gamma_{\mathrm{E}}=q_{\max } \frac{S_{\mathrm{S}}}{\left(K_{\mathrm{S}}+S_{\mathrm{S}}\right)} \frac{C_{\mathrm{I}}}{K_{\mathrm{I}}+C_{\mathrm{I}}} \frac{S_{\mathrm{O}}}{K_{\mathrm{O}}+S_{\mathrm{O}}} X_{\mathrm{H}}$ 
Table 1 Matrix of the activated sludge model with energy spilling

\begin{tabular}{|c|c|c|c|c|c|c|}
\hline Component process & $\mathrm{S}_{\mathrm{o}} \mathrm{O}_{2}$ & $\mathrm{~S}_{\mathrm{s}} \mathrm{COD}$ & $\mathrm{X}_{\mathrm{S}} \mathrm{COD}$ & $\mathrm{X}_{\mathrm{I}} \mathrm{COD}$ & $\mathrm{X}_{\mathrm{H}} \mathrm{COD}$ & Process rate expression \\
\hline Growth with inhibition & $\frac{-\left(1-Y_{\mathrm{H}}\right)}{Y_{\mathrm{H}}}$ & $\frac{-1}{Y_{\mathrm{H}}}$ & & & 1 & $\mu_{\max } \frac{S_{\mathrm{S}}}{\left(K_{\mathrm{S}}+S_{\mathrm{S}}\right)\left(1+C_{\mathrm{I}} / K_{\mathrm{I}}\right)} \frac{S_{\mathrm{O}}}{K_{\mathrm{O}}+S_{\mathrm{O}}} X_{\mathrm{H}}$ \\
\hline Maintenance & -1 & -1 & & & & $m \frac{S_{\mathrm{S}}}{\left(K_{\mathrm{S}}+S_{\mathrm{S}}\right)\left(1+C_{\mathrm{I}} / K_{\mathrm{I}}\right)} \frac{S_{\mathrm{O}}}{K_{\mathrm{O}}+S_{\mathrm{O}}} X_{\mathrm{H}}$ \\
\hline Energy spilling & -1 & -1 & & & & $q_{\max } \frac{S_{\mathrm{S}}}{\left(K_{\mathrm{S}}+S_{\mathrm{S}}\right)} \frac{C_{\mathrm{I}}}{K_{\mathrm{I}}+C_{\mathrm{I}}} \frac{S_{\mathrm{O}}}{K_{\mathrm{O}}+S_{\mathrm{O}}} X_{\mathrm{H}}$ \\
\hline Decay & & & $1-f_{\mathrm{I}}$ & $f_{\mathrm{I}}$ & -1 & $b_{\mathrm{H}} X_{\mathrm{H}}$ \\
\hline Hydrolysis & & 1 & -1 & & & $k \frac{X_{\mathrm{S}} / X_{\mathrm{H}}}{K_{\mathrm{X}}+X_{\mathrm{S}} / X_{\mathrm{H}}} X_{\mathrm{H}}$ \\
\hline
\end{tabular}

In the presence of metabolic uncouplers, the microbial growth efficiency is much lowered in uncouplercontaining microbial culture. With the increasing uncoupler concentration, the growth rate of activated sludge reduced significantly (Chen et al. 2006a, b, 2008). The noncompetitive inhibition model is adopted in this study to model the growth of activated sludge in the presence of uncouplers. The kinetic expressions are defined as shown as below:

$\mu=\mu_{\max } \frac{S_{\mathrm{S}}}{\left(K_{\mathrm{S}}+S_{\mathrm{S}}\right)\left(1+C_{\mathrm{I}} / K_{\mathrm{I}}\right)} \frac{S_{\mathrm{O}}}{K_{\mathrm{O}}+S_{\mathrm{O}}} X_{\mathrm{H}}$.

The stoichiometry for maintenance process is the same as energy spilling process. However, the maintenance rate is different from the energy spilling rate in the following two aspects. First, the maintenance coefficient $(m)$ is much smaller than the energy spilling coefficient $\left(q_{\max }\right)$. Secondly, the maintenance rate expression is in accord with the growth rate expression, which multiplies a factor $\left(\frac{1}{1+C_{\mathrm{I}} / K_{\mathrm{I}}}\right)$ in substrate consumption expression. The maintenance rate is expressed as follows:

$\gamma_{\mathrm{m}}=m \frac{S_{\mathrm{S}}}{\left(K_{\mathrm{S}}+S_{\mathrm{S}}\right)\left(1+C_{\mathrm{I}} / K_{\mathrm{I}}\right)} \frac{S_{\mathrm{O}}}{K_{\mathrm{O}}+S_{\mathrm{O}}} X_{\mathrm{H}}$

The decay rate of microorganisms is first-order with biomass:

$\gamma_{\mathrm{D}}=b_{\mathrm{H}} X_{\mathrm{H}}$
The hydrolysis process is, presumably, to be the ratelimiting step with a rate characterized by surface reaction kinetics as done in ASM models.

$\gamma_{\mathrm{H}}=k \frac{X_{\mathrm{S}} / X_{\mathrm{H}}}{K_{\mathrm{X}}+X_{\mathrm{S}} / X_{\mathrm{H}}} X_{\mathrm{H}}$

A computer program, AQUASIM 2.0 (Reichert et al. 1994), is used for modeling the biological processes in activated sludge. AQUASIM 2.0 is a program designed mainly for estimating the coefficients and parameters involved in a bioreaction model. This program offers flexible definition of the kinetic model, flow scheme, and process control strategies; it also provides support for graphic display of the support of the simulation results, corresponding experimental data, and communication with spreadsheet programs (Reichert et al. 1994).

\section{Results}

Sensitivity analysis

The sensitivity analysis in this study was performed with the adjusted main parameters to evaluate their effects on the substrate consumption profiles using one variable at a time approach. Three main parameters $\left(K_{\mathrm{S}}, \mu_{\max }\right.$, and $\left.Y_{\mathrm{H}}\right)$ were selected to perform the sensitivity analysis. Model coefficients were changed in the simulation one by one in an appropriate range. The sensitivities of the substrate consumption to the changes in these parameters were determined and are shown in Fig. 1.
Table 2 Components of the developed model

\begin{tabular}{lll}
\hline Symbol & Unit & Definition \\
\hline$S_{\mathrm{O}}$ & $\mathrm{mg} \mathrm{l}^{-1}$ & Dissolved oxygen concentration \\
$S_{\mathrm{S}}$ & $\mathrm{mg} \mathrm{l}^{-1}$ & Substrate concentration \\
$X_{\mathrm{S}}$ & $\mathrm{mg} \mathrm{l}^{-1}$ & Concentration of slowly hydrolyzed particulate substrate \\
$X_{\mathrm{I}}$ & $\mathrm{mg} 1^{-1}$ & Concentration of particulate inert \\
$X_{\mathrm{H}}$ & $\mathrm{mg} \mathrm{l}^{-1}$ & Concentration of heterotrophic biomass \\
$C_{\mathrm{I}}$ & $\mathrm{mg} \mathrm{l}^{-1}$ & Concentration of inhibitor \\
\hline
\end{tabular}



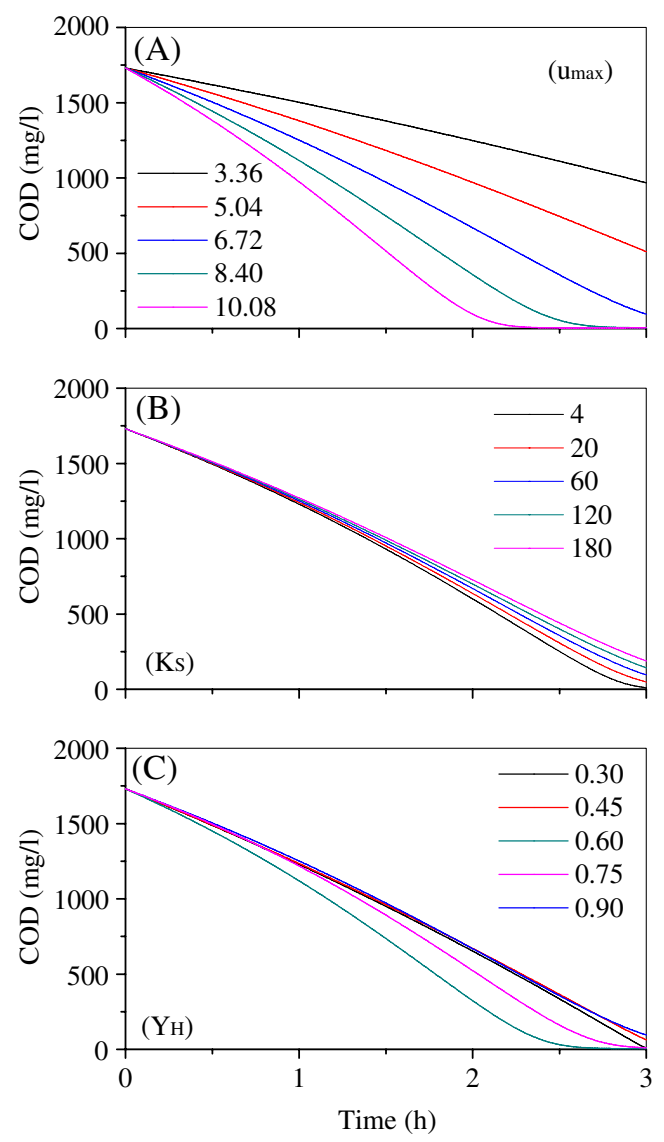

Fig. 1 Sensitivity analysis of $K_{\mathrm{S}}, \mu_{\max }$, and $Y_{\mathrm{H}}$

The effect of the varying maximum microbial growth rate $\mu_{\max }\left(\right.$ day $\left.^{-1}\right)$ on the substrate consumption profiles is illustrated in Fig. 1a. The base value for $\mu_{\max }$ was 6.72 $\left(\right.$ day $^{-1}$ ) with a range of $3.36 \leq \mu_{\max } \leq 10.08$. As $\mu_{\max }$ increased, the substrate consumption rate increased significantly. On the other hand, the time period for the substrate depleted was shortened as $\mu_{\max }$ increased. For instance, substrate became nearly depleted in $2 \mathrm{~h}$ at $\mu_{\max }$ of 10.08. At $\mu_{\max }$ of 3.36 , only about $500 \mathrm{mg} \mathrm{l}^{-1}$ of substrate was consumed in $2 \mathrm{~h}$. Figure 1a clearly shows that the substrate consumption was highly dependent of the $\mu_{\max }$ value.

The sensitivity analysis of the substrate consumption to the affinity constant for substrate growth $\left(K_{\mathrm{S}}\right)$ was performed in a range of $4 \leq K_{\mathrm{S}} \leq 180$. The value of $K_{\mathrm{S}}(4-180 \mathrm{mg} \mathrm{COD} / \mathrm{L})$ in this study was much higher than the default values in ASM (4-20 mg COD/L). However, as shown in Fig. 1b, $K_{\mathrm{S}}$ had no substantial effect on the substrate consumption. Thus, this constant value did not significantly affect the results. As shown in Fig. 1c, the yield coefficient of microbial $Y_{\mathrm{H}}$ had an influence on the model output in an opposite way. A lower $Y_{\mathrm{H}}$ value resulted in a higher substrate consumption rate. This is attributed to the indirect effect of this yield on the substrate utilization rate through influencing the substrate electron distribution. The sensitivity of the new model parameter $q_{\max }$ was analyzed, and it was found that this parameter had no significant effect on the substrate consumption (data not shown).

Because of the highly dependence in substrate consumption, $\mu_{\max }$ and $Y_{\mathrm{H}}$ in our model should be determined again in different systems. The same affinity constant for substrate $\left(K_{\mathrm{S}}\right)$ was used in this study because of its low sensitivity. Such sensitivity analysis results would be used in model evaluation.

\section{Model calibration}

Model calibration procedure is a process of adjusting coefficient values of the model so that the results produced
Table 3 Stoichiometric and kinetic parameters of the developed model
1 Gujer et al. (1999), 2 Henze et al. (1987), 3 Moussa et al. (2005), 4 This study

\begin{tabular}{|c|c|c|c|c|}
\hline Parameter & Value & Unit & Definition & Source \\
\hline$k$ & 3 & mg COD mg ${ }^{-1}$ COD day ${ }^{-1}$ & Hydrolyze rate & 1 \\
\hline$K_{\mathrm{I}}$ of dNP & 8.5 & $\mathrm{mg} 1^{-1}$ & Inhibition coefficient & 4 \\
\hline$K_{\mathrm{I}}$ of $\mathrm{dCP}$ & 110 & $\mathrm{mg} 1^{-1}$ & Inhibition coefficient & 4 \\
\hline$K_{\mathrm{S}}$ & 120 & $\mathrm{mg} 1^{-1}$ & Affinity constant for substrate & 4 \\
\hline$K_{\mathrm{O}}$ & 0.2 & $\operatorname{mg~} 1^{-1}$ & Affinity constant for oxygen & 2 \\
\hline$K_{\mathrm{X}}$ & 0.03 & $\mathrm{mg} \mathrm{COD} \mathrm{mg}^{-1} \mathrm{COD}$ & Affinity constant for hydrolyze & 1 \\
\hline$f_{\mathrm{I}}$ & 0.2 & - & Fraction of $X_{\mathrm{I}}$ in decay & 2 \\
\hline$\mu_{\max }$ of dNP & 6.72 & day $^{-1}$ & Maximum specific growth rate & 4 \\
\hline$\mu_{\max }$ of $\mathrm{dCP}$ & 7.20 & day $^{-1}$ & Maximum specific growth rate & 4 \\
\hline$m$ & 0.12 & mg COD mg ${ }^{-1} X_{\mathrm{H}}$ COD day ${ }^{-1}$ & Maintenance coefficient & 3 \\
\hline$q_{\max }$ of $\mathrm{dNP}$ & 5.52 & day $^{-1}$ & Energy spilling coefficient & 4 \\
\hline$q_{\max }$ of $\mathrm{dCP}$ & 1.58 & day $^{-1}$ & Energy spilling coefficient & 4 \\
\hline$b_{\mathrm{H}}$ & 0.8 & day $^{-1}$ & Decay coefficient & 3 \\
\hline$Y_{\mathrm{H}}$ of $\mathrm{dNP}$ & 0.60 & $\mathrm{mg}$ COD $\mathrm{mg}^{-1} \mathrm{COD}$ & Yield coefficient & 4 \\
\hline$Y_{\mathrm{H}}$ of $\mathrm{dCP}$ & 0.62 & $\mathrm{mg} \mathrm{COD} \mathrm{mg}^{-1} \mathrm{COD}$ & Yield coefficient & 4 \\
\hline
\end{tabular}


Table 4 Experimental data from Chen et al. (2006a)

\begin{tabular}{|c|c|c|c|c|c|c|c|c|}
\hline \multirow[t]{3}{*}{ Time (min) } & \multicolumn{8}{|c|}{ Concentration of $\mathrm{dCP}\left(\mathrm{mgl}^{-1}\right)$} \\
\hline & 0 & 1 & 2 & 5 & 8 & 10 & 15 & 20 \\
\hline & \multicolumn{8}{|c|}{$\mathrm{COD}\left(\mathrm{mgl}^{-1}\right)$} \\
\hline 0 & 2,276 & 2,276 & 2,276 & 2,276 & 2,276 & 2,276 & 2,276 & 2,276 \\
\hline 30 & 1,695 & 1,693 & 1,690 & 1,735 & 1,768 & 1,742 & 1,767 & 1,767 \\
\hline 60 & 1,497 & 1,502 & 1,531 & 1,555 & 1,557 & 1,557 & 1,556 & 1,591 \\
\hline 90 & 1,311 & 1,318 & 1,336 & 1,354 & 1,347 & 1,353 & 1,399 & 1,417 \\
\hline 120 & 1,148 & 1,164 & 1,160 & 1,186 & 1,204 & 1,196 & 1,252 & 1,232 \\
\hline 160 & 916 & 932 & 932 & 945 & 959 & 946 & 1,007 & 1,006 \\
\hline
\end{tabular}

by the model with these coefficients closely agree with the experimental data. The parameter values are calibrated with the objective function given as follows:

$\chi^{2}(p)=\sum_{i=1}^{n}\left(\frac{y_{\text {meas }, i}-y_{i}(p)}{\sigma_{\text {meas }, i}}\right)^{2}$

In this equation, $y_{\text {meas }, i}$ is the $i$-th measurement; $\sigma_{\text {meas }, i}$ is its standard deviation; and $y_{i}(p)$ is the calculated value of the model variable corresponding to the $i$-th measurement and evaluated at the time and location of this measurement, $p=$ $\left(p_{1}, \ldots, p_{m}\right)$ are the model parameters, and $n$ is the number of data points.

The substrate consumption in the presence of uncoupler was fitted. Three parameters, the maximum specific growth rate $\left(\right.$ day $\left.^{-1}\right)$, the energy spilling coefficient $\left(\right.$ day $\left.^{-1}\right)$, and the sludge yield coefficient (mg COD mg ${ }^{-1} \mathrm{COD} ; \mu_{\max }, q_{\max }$, and $Y_{\mathrm{H}}$ ), were used to fit the substrate consumption results. In the batch tests, $\mu_{\max }$ is regarded to be constant. The inhibition coefficient of microbial growth $K_{\mathrm{I}}$ could be calculated according to the relative specific growth rate $\left(\mu / \mu_{\mathrm{O}}\right)$ at different uncoupler concentrations. Other stoichiometric and kinetic parameters needed for the model listed in Table 3 are mainly derived from the literature. The substrate consumption and the observed yield coefficient $\left(Y_{\mathrm{obs}}\right)$ of activated sludge at different uncoupler concentrations were fitted. The observed yield coefficient of activated sludge in this study was calculated as follows:

$Y_{\mathrm{obs}}=\frac{\Delta X_{\mathrm{H}}+\Delta X_{\mathrm{I}}+\Delta X_{\mathrm{S}}}{\Delta C O D}=\frac{\int_{0}^{t} \frac{d X_{\mathrm{H}}}{d t}+\int_{0}^{t} \frac{d X_{\mathrm{I}}}{d t}+\int_{0}^{t} \frac{d X_{\mathrm{S}}}{d t}}{\Delta C O D}$

$$
\begin{aligned}
\frac{d X_{\mathrm{H}}}{d t}= & u_{\max } \frac{S_{\mathrm{S}}}{\left(K_{\mathrm{S}}+S_{\mathrm{S}}\right)\left(1+C_{\mathrm{I}} / K_{\mathrm{I}}\right)} \frac{S_{\mathrm{O}}}{K_{\mathrm{O}}+S_{\mathrm{O}}} X_{\mathrm{H}} \\
& -b_{\mathrm{H}} X_{\mathrm{H}}
\end{aligned}
$$

$$
\frac{d X_{\mathrm{I}}}{d t}=f_{\mathrm{I}} b_{\mathrm{H}} X_{\mathrm{H}}
$$

$\frac{d X_{\mathrm{S}}}{d t}=\left(1-f_{\mathrm{I}}\right) b_{\mathrm{H}} X_{\mathrm{H}}-k \frac{X_{\mathrm{S}} / X_{\mathrm{H}}}{K_{\mathrm{X}}+X_{\mathrm{S}} / X_{\mathrm{H}}} X_{\mathrm{H}}$

$$
\Delta \mathrm{COD}=\mathrm{COD}(\text { Influent })-\mathrm{COD} \text { (Effluent })
$$

\begin{tabular}{|c|c|c|c|c|c|c|c|c|}
\hline \multirow[t]{3}{*}{ Time (min) } & \multicolumn{8}{|c|}{ Concentration of $\mathrm{dNP}\left(\mathrm{mgl}^{-1}\right)$} \\
\hline & 0 & 1 & 2 & 5 & 8 & 10 & 15 & 20 \\
\hline & \multicolumn{8}{|c|}{$\operatorname{COD}\left(\mathrm{mgl}^{-1}\right)$} \\
\hline 0 & 1,730 & 1,730 & 1,730 & 1,730 & 1,730 & 1,730 & 1,730 & 1,730 \\
\hline 30 & 1,250 & 1,260 & 1,275 & 1,300 & 1,400 & 1,450 & 1,475 & 1,500 \\
\hline 60 & 831 & 831 & 866 & 872 & 791 & 953 & 960 & 1,006 \\
\hline 90 & 650 & 630 & 650 & 670 & 700 & 800 & 900 & 920 \\
\hline 120 & 468 & 468 & 355 & 389 & 438 & 657 & 870 & 840 \\
\hline 150 & 330 & 300 & 280 & 300 & 430 & 600 & 710 & 830 \\
\hline 180 & 195 & 149 & 156 & 206 & 428 & 544 & 720 & 820 \\
\hline
\end{tabular}

Table 5 Experimental data from Chen et al. (2006b) 
Table 6 Experimental data of sludge yield from Chen et al. (2006a, b)

\begin{tabular}{lll}
\hline Concentration $(\mathrm{mg} / \mathrm{l})$ & \multicolumn{2}{l}{ Yield $\left(\mathrm{mg} \mathrm{SS} \mathrm{mg}^{-1} \mathrm{COD}\right)$} \\
\cline { 2 - 3 } & $\mathrm{dNP}$ & $\mathrm{dCP}$ \\
\hline 0 & 0.67 & 0.64 \\
1 & 0.56 & 0.63 \\
2 & 0.57 & 0.62 \\
5 & 0.54 & 0.63 \\
8 & 0.51 & 0.60 \\
10 & 0.37 & 0.63 \\
15 & 0.32 & 0.61 \\
20 & 0.30 & 0.59 \\
\hline
\end{tabular}

\section{Discussion}

Model evaluation and verification

The model evaluation was performed from the comparison between the measured and calculated results. The experimental data of the two related case studies shown in Tables 4, 5, and 6 were used for model evaluation. Different uncouplers, activated sludge, and operation conditions were involved in the model evaluation. It should be noted that different wastewater characteristics, reactor operating conditions, and microbial communities might result in a variation of the obtained parameter values, as shown in Table 3, as the model parameters are highly dependent on the factors above.
Case I: Model evaluation with experimental data of Chen et al. (2006b)

The model was calibrated with the results shown in Table 4. At $5 \mathrm{mg}^{-1}$ of dNP in batch tests, the values of 6.72 day $^{-1}$ for the maximum specific growth rate $\left(\mu_{\max }\right)$ and $0.60 \mathrm{mg}$ COD $\mathrm{mg}^{-1} \mathrm{COD}$ for yield coefficient $\left(Y_{\mathrm{H}}\right)$ were estimated from the experimental data without additional dNP by using AQUASIM. Then, with these coefficients, the energy spilling coefficient $\left(q_{\max }\right)$ of 5.52 day $^{-1}$ was estimated from the experimental data at $5 \mathrm{mg}^{-1}$ of dNP.

With the three parameter values obtained above, the predicted substrate consumptions, and the sludge yields matched the experimental results in both presence and absence of dNP, as shown in Figs. 2 and 3. In addition, the model was able to appropriately simulate the effects of dNP concentration on the substrate consumption and the sludge yield in the tests.

Case II: Model evaluation with experimental data of Chen et al. (2006a)

The values of 1.58 day $^{-1}$ for $q_{\max }, 7.20$ day $^{-1}$ for $\mu_{\max }$, and $0.62 \mathrm{mg}$ COD mg${ }^{-1}$ COD for $Y_{\mathrm{H}}$ were estimated with experimental results at $\mathrm{dCP}$ of $5 \mathrm{mg}^{-1}$. With these values, the model predicted the substrate consumptions and the sludge yields in the batch tests well (Figs. 4 and 5). Again, the model was also able to predict the effects of dCP dosage on the substrate consumption and the sludge yield in the tests.

The sludge yield was $0.64 \mathrm{mg} \mathrm{SS} / \mathrm{mg}$ COD for the control, while it was decreased to $0.59 \mathrm{mg} \mathrm{SS} / \mathrm{mg} \mathrm{COD}$ at
Fig. 2 COD degradation profiles at different dNP concentrations. Black linesimulated with our model; red line - simulated with ASM; and triangle - measured results
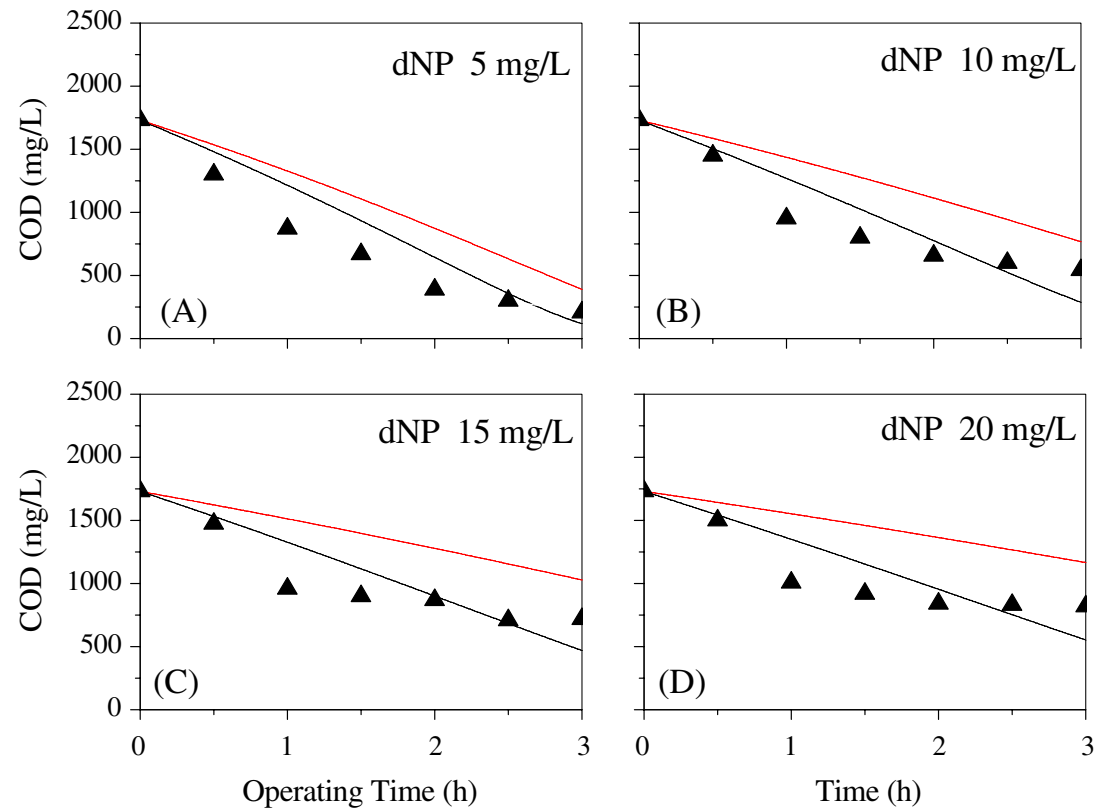


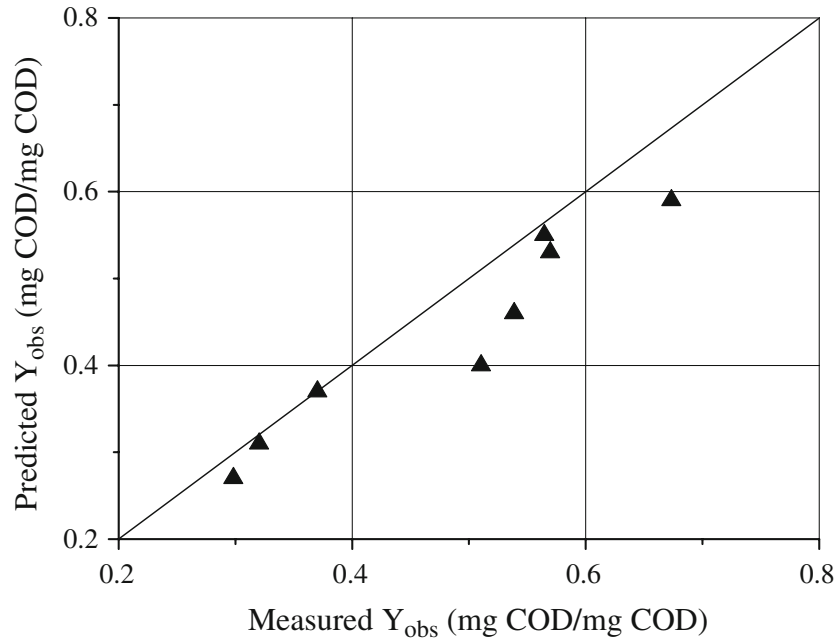

Fig. 3 The predicted and measured sludge yields in the presence of dNP

$\mathrm{dCP}$ of $20 \mathrm{mg} / \mathrm{l}$. Figure 5 shows that the predicted and measured results matched well. Even though the change of the measured yield coefficient value was very limited, the model developed in this work was able to predict such a minor change.

Model comparison

Figure 2 shows the simulation results in the presence of dNP with our developed model and the ASM without a consideration of energy spilling. As shown in Fig. 2, our model with a consideration of energy spilling matched the experimental results well. On the other hand, the

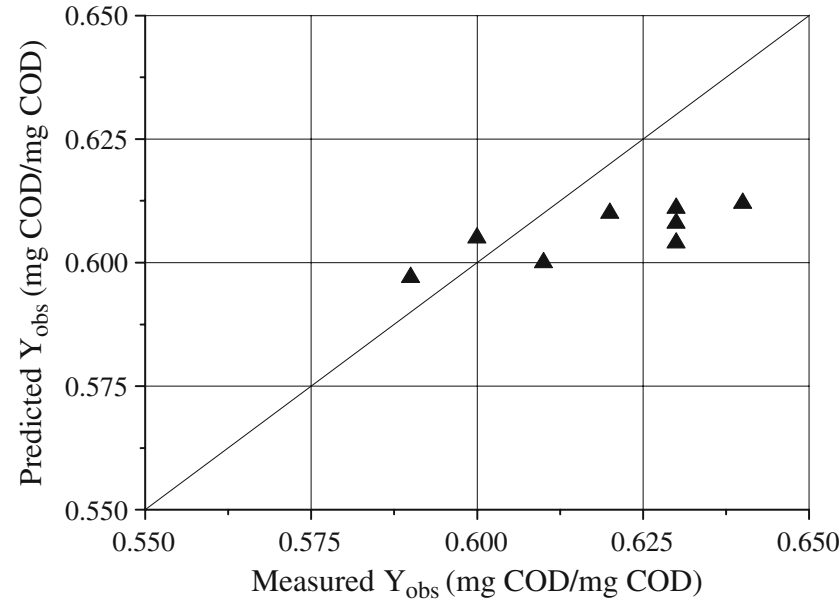

Fig. 5 Predicted and measured sludge yields in the presence of $\mathrm{dCP}$

conventional models without consideration of energy spilling were not able to simulate the measured substrate consumption results. The discrepancy between the simulated, and measured results increased with an increase in dNP concentration. This demonstrates that the energy spilling should be taken into account when modeling the activated sludge process in the presence of metabolic uncouplers.

Energy spilling rate was highly depended on energy spilling coefficient $\left(q_{\max }\right)$ and uncoupler concentration $\left(C_{\mathrm{I}}\right)$. Cook and Russell (1994) found that the spilling energy was ten times of the maintenance energy for a pure culture, Streptococcus bovis. In our work, the energy spilling coefficient $\left(q_{\max }=5.52 \mathrm{day}^{-1}\right)$ is over ten times of the maintenance coefficient. This implies that the mixed
Fig. 4 COD degradation profiles at different dCP concentrations. Line-simulated results with our model; and triangle-measured results
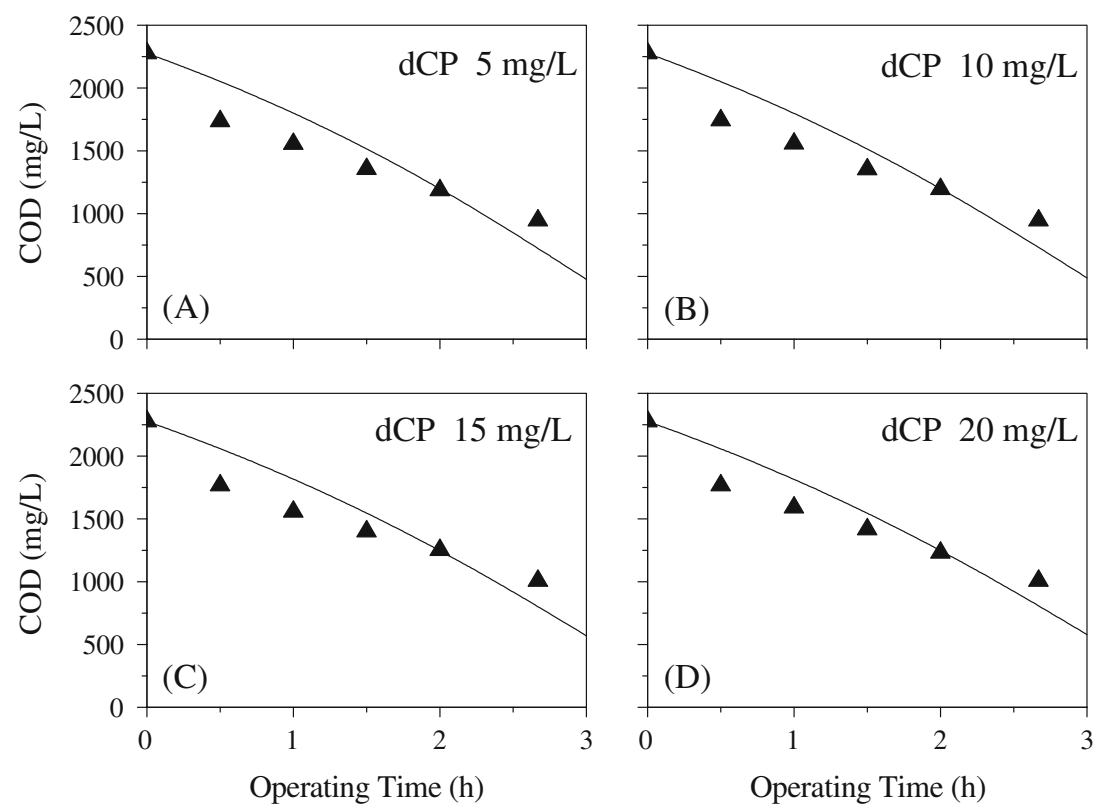
cultures might have a different response to the metabolic uncouplers compared with a single culture.

Chemical uncouplers in batch cultures can cause an energy spilling, resulting in significant nongrowth-associated substrate consumption. A rather simple kinetic model with noncompetitive inhibition growth and energy spilling was developed in this study, and it was verified by the measured substrate consumption and sludge yield data. The excess sludge could be reduced through the dose of an appropriate concentration of uncouplers without severely inhibiting the substrate consumption efficiency and rate. The mechanisms for the energy spilling and sludge reduction by uncouplers in real wastewater treatment systems warrant further investigations.

Acknowledgments The authors wish to thank the Natural Science Foundation of China (50625825 and 50738006) and the Key Special Program on the Science and Technology for the Pollution Control and Treatment of Water Bodies (2008ZX07316-002 and 2008ZX07010005) for the partial support of this study.

\section{References}

Chen GH, Mo HK, Liu Y (2002) Utilization of a metabolic uncoupler, 3, 3, 4', 5-tetrachilrosalicylanilide (TCS) to reduce sludge growth in activated sludge culture. Water Res 36:2077-2083

Chen GW, Yu HQ, Liu HX, Xu DQ (2006a) Response of activated sludge to the presence of 2, 4-dichlorophenol in a batch culture system. Process Biochem 41:1758-1763

Chen GW, Yu HQ, Xi PG (2006b) Influence of 2, 4-dinitrophenol on the characteristics of activated sludge in batch reactors. Bioresource Technol 98:729-733

Chen GW, Yu HQ, Xi PG, Xu DQ (2008) Modeling the yield of activated sludge in the presence of 2, 4-dinitrophenol. Biochem Eng J 40:10-50-156
Cook M, Russell B (1994) Energy spilling reactions of Streptococcus bovis and resistance of its membrane to proton conductance. Appl Environ Microbiol 60:1942-1948

Forrest WW (ed) (1969) Energetic aspects of microbial growth. Microbial Energetics. Cambridge University Press, London

Gujer W, Larsen TA (1995) The implementation of biokinetics and conservation principles in ASIM. Water Sci Technol 31:257-266

Gujer W, Henze M, Mino T, van Loosdrecht MCM (1999) Activated sludge model no. 3. Water Sci Technol 39:183-193

Henze M, Grady CPL Jr, Gujer W, Marais GVR, Matsuo T (1987) Activated sludge model No. 1. Scientific and Technical Report No. 1. IAWPRC, London

Henze M, Gujer W, Mino T, van Loosdrecht MCM (2000) Activated Sludge Models ASM1, ASM2, ASM2d, and ASM3. IWA Scientific and Technical Report No. 9. IWA Publishing, London, UK

Liu Y (2003) Chemically reduced excess sludge production in the activated sludge process. Chemosphere 50:1-7

Liu Y, Chen GH, Rols JL (1999) A kinetic model incorporating energy spilling for substrate removal in substrate-sufficient batch culture of activated sludge. Appl Microbiol Biotechnol 52:647-651

Low EW, Chase HA (1999) Reducing production of excess biomass during wastewater treatment. Water Res 33:1119-1132

Mitchell P, Moyle J (1965) Stoichiometry of proton translocation through the respiration chain and adenosine triphosphatase system of rat liver mitochondria. Nature 208:147

Moussa MS, Hooijmans CM, Lubberding HJ, Gijzen HJ, van Loosdrecht MCM (2005) Modelling nitrification, heterotrophic growth and predation in activated sludge. Water Res 39: 5080-5098

Reichert P, Ruchti J, Simon W (1994) Aquasim 2.0. Swiss Federal Institute for Environmental Science and Technology (EAWAG), Duebendorf, Switzerland

Saini G, Wood BD (2008) Metabolic uncoupling of Shewanella oneidensis MR-1, under the influence of excess substrate and 3, 3', 4', 5-tetrachlorosalicylanilide (TCS). Biotechnol Bioeng 99:1352-1360

Tempest W, Niejssel M (1992) Physicological and energetic aspects of bacterial metabolite overproduction. FEMS Microbiol 64: 91-99

Tsai SP, Lee YH (1990) A model for energy-sufficient culture growth. Biotechnol Bioeng 35:138-145 